\title{
Efeito da adubação nitrogenada na formação de mudas de goiabeira irrigadas com águas salinizadas
}

\section{Effect of nitrogen fertilization in the formation of guava seedlings irrigated with salted water}

\author{
Evandro Manoel da Silva $*^{1}$, Reginaldo Gomes Nobre ${ }^{2}$, Leandro de Pádua Souza ${ }^{3}$, Francisco Wesley Alves Pinheiro ${ }^{4}$; \\ Anderson Bruno Anacleto de Andrade 4
}

\begin{abstract}
Resumo: Além de favorecer o desenvolvimento e a produção das culturas, a adubação tem sido considerada uma técnica capaz de reduzir o efeito da salinidade nas plantas. Neste sentido, desenvolveu-se o trabalho para avaliar a influência de doses de nitrogênio na formação de mudas de goiabeira cv. Paluma irrigadas com águas de diferentes salinidades. O experimento foi desenvolvido em casa de vegetação do Centro de Ciências e Tecnologia Agroalimetar da UFCG, Pombal, PB com delineamento experimental em blocos casualizados, em esquema fatorial $5 \mathrm{x} 4$, sendo os tratamentos correspondentes aos níveis de condutividade elétrica da água $(\mathrm{CEa})$ de 0,$3 ; 1,1 ; 1,9 ; 2,7$ e $3,5 \mathrm{dS} \mathrm{m}^{-1}$ associados a 70, 100,130 e $160 \%$ da dose recomendada de nitrogênio $(\mathrm{N})$ para mudas de goiabeira cv. Paluma, com quatro repetições, e cinco plantas por unidade experimental. Aos 180 dias após a emergência, a adubação nitrogenada na dose de $773 \mathrm{mg} \mathrm{de} \mathrm{N} \mathrm{dm}^{-3} \mathrm{reduz}_{\mathrm{o}}$ efeito da salinidade da água de irrigação sobre o diâmetro do caule das mudas. As plantas adubadas com as doses variando de 541 a $618,4 \mathrm{mg} \mathrm{de} \mathrm{N} \mathrm{dm}^{-3}$ atingem maior crescimento em altura de planta, número de folhas e área foliar. A área foliar e a massa seca total de mudas de goiabeira atingem maiores valores no nível de $\mathrm{CEa}$ de $1,3 \mathrm{dS} \mathrm{m} \mathrm{m}^{-1}$.
\end{abstract}

Palavras-chaves: Psidium guajava L., estresse salino, adubação.

\begin{abstract}
In addition to favoring the development and production of crops, the fertilizer has been considered a technique capable to reduce the effect of salinity on plants. The experiment was conducted in a greenhouse of the 'Centro de Ciências e Tecnologia Agroalimentar' of UFCG, Pombal, PB in a randomized block design a 5 x 4 factorial, with the treatments corresponding to the electrical conductivity of irrigation water (ECw) $0.3 ; 1.1 ; 1.9 ; 2.7$ and $3.5 \mathrm{dS} \mathrm{m}^{-1}$ associated with doses of 70, 100, 130 and 160\% of recommended nitrogen $(\mathrm{N})$ for guava seedlings Paluma, with four replications, using five plants per experimental unit. At 180 days after emergence, the nitrogen fertilization at a dose of $773 \mathrm{mg} \mathrm{N} \mathrm{dm}^{-3}$ reduces the effect of irrigation water salinity on the stem diameter of seedlings. The plants fertilized with doses ranging from 541 at $618.4 \mathrm{mg}$ of the $\mathrm{N} \mathrm{dm}^{-3}$ reach higher growth in plant height, leaf number and leaf area. The leaf area and total dry mass of guava seedlings reach higher values at the $\mathrm{ECw}$ level of $1.3 \mathrm{dS} \mathrm{m}^{-1}$.
\end{abstract}

Key words: Psidium guajava L., salt stress, fertilization

\footnotetext{
*Autor paracorrespondência

Recebido para publicação em 15/08/2015; aprovado em 01/10/2015

${ }^{1}$ Mestre em Agronomia - Horticultura Tropical, CCT A/UFCG, Pombal,Paraíba, Brasil.Fone (83) 981 16-1622. E-mail: evandroagroman@ hotmail.com;

${ }^{2}$ Eng. Agrônomo, Professor Adjunto III, CCTA/UFCG, P ombal, Paraíba, Brasil.E-mail: rgomesnobre@pq.cnpq.br;

${ }^{3}$ Mestrando em Horticultura Tropical, CCTA/UFCG, Pombal, Paraíba, Brasil .Email: engenheiropadua@hotmail.com;

${ }^{4}$ Graduando em Agronomia , Universidade Federal de Campina Grande. E-mail: wesley.ce@ @otmail.com; bdeandrade3@gmail.com
} 


\section{INTRODUÇÃO}

A goiabeira é uma espécie disseminada em todas as regiões subtropicais e tropicais do mundo, devido a sua fácil adaptação a diferentes condições edafoclimáticas. No Nordeste Brasileiro, é uma das fruteiras que vem sendo cultivadas com sucesso sob irrigação (GONZAGA NETO et al., 2007), tornando a região a segunda maior produtora do fruto no país com 42,2\% da produção Nacional (IBGE, 2012).

A irregularidade na distribuição de chuvas, altas temperaturas e elevadas taxas de evapotranspiração tem limitado a disponibilidade de água de boa qualidade no semiárido nordestino, onde se tem tornado necessário o uso de água salina na irrigação como uma alternativa para suprir a demanda hídrica das culturas, principalmente no período de estiagem, quando os poços e açudes da região apresentam níveis de sais mais elevados na água (SILVA JÚNIOR et al., 1999). Esta atividade, realizada continuamente, chega a comprometer a qualidade do solo e a produtividade das culturas (NEVES et al., 2009), inclusive da goiabeira.

Vários autores verificaram que o aumento na salinidade da água de irrigação afeta negativamente a formação de mudas de goiabeira, provocando reduções sobre o crescimento em altura, diâmetro do caule, número de folhas, área foliar e acúmulo de matéria seca nas plantas, incluindo as cultivares de goiabeira 'Paluma', 'Ogawa', 'Rica', 'Pentecoste', 'Surubim' e 'IPA-B38' (TÁ VORA et al., 2001; CAVALCANTE et al., 2005; GURGEL et al., 2007; CAVALCANTE et al., 2010).

Em geral, a salinidade inibe o crescimento das plantas, em função dos efeitos tóxicos dos íons $\mathrm{Na}^{+}$e $\mathrm{Cl}^{-}$e à redução do potencial osmótico do solo (MUNNS, 2005). Além disso, provoca deficiência nutricional de $\mathrm{K}^{+}, \mathrm{Ca}^{2+}{\mathrm{e} \mathrm{Mg}^{2+} \text { induzida }}^{2}$ pela competição com o $\mathrm{Na}^{+}$, ou mesmo do $\mathrm{N}$ pela alta concentração de $\mathrm{Cl}^{-}$, devido à competição com o $\mathrm{NO}_{3}{ }^{-}$(APSE; BLUMWALD, 2007).

O uso da adubação nitrogenada já é considerada uma das técnicas que pode ser utilizada na redução do estresse salino em algumas espécies de plantas, como no caso do tomateiro (Blanco et al., 2008) e da mamoneira (SOARES et al., 2012). Sobretudo, não se encontra relatos descrevendo esta ocorrência na cultura da goiabeira.

De acordo com Franco et al. (2007) o nitrogênio está entre os nutrientes mais exigidos por esta cultura, sendo o segundo acumulado em maior quantidade em mudas da espécie pelas cultivares Paluma e Século XXI. Dias et al. (2012) ressaltam que a adubação nitrogenada na dose adequada têm papel fundamental no crescimento, acúmulo de matéria seca e qualidade de mudas goiabeira.

Diante o exposto, objetivou-se com o trabalho avaliar a influência de doses de nitrogênio na formação de mudas de goiabeira cv. Paluma irrigadas com águas de diferentes salinidades.

\section{MATERIAL E MÉTODOS}

O experimento foi conduzido em cas a de vegetação, no Centro de Ciências e Tecnologia Agroalimentar (CCTA) da Universidade Federal de Campina Grande (UFCG), Pombal $\mathrm{PB}$, cujas coordenadas geográficas locais de referência são 6 48'16" S, 3749'15" O e altitude média de $144 \mathrm{~m}$ (SOARES et al., 2012). Segundo a classificação de Köppen, adaptada ao Brasil, o clima da região é classificado como BSh, semiárido quente, temperatura média de $28^{\circ} \mathrm{C}$, precipitações pluviométricas em torno de $750 \mathrm{~mm} \mathrm{ano}^{-1}$.

Os tratamentos resultaram de dois fatores: salinidade da água de irrigação em cinco níveis (CEa): 0,$3 ; 1,1 ; 1,9 ; 2,7$ e $3,5 \mathrm{dS} \mathrm{m}^{-1}$ e quatro doses de nitrogênio: $70,100,130$ e $160 \%$ da dose de $\mathrm{N}$ indicada para mudas de goiabeira, ou seja, 541; 773; 1005 e $1237 \mathrm{mg}$ de $\mathrm{N} \mathrm{dm}^{-3}$, aleatorizados em blocos, com quatro repetições, sendo cada unidade experimental compostas por cinco plantas, onde foi utilizada duas plantas para avaliação.

Os níveis salinos foram selecionados de acordo com citações de Távora et al. (2001) que classificaram a goiabeira na fase de crescimento inicial como sensível à salinidade, com a salinidade limiar no extrato de saturação do solo (CEes) e na água de irrigação (CEa) de $1,2 \mathrm{dS} \mathrm{m} \mathrm{m}^{-1}$ e $0,8 \mathrm{dS}$ $\mathrm{m}^{-1}$, respectivamente. As doses de $\mathrm{N}$ foram determinadas com base na dose de $773 \mathrm{mg}$ de $\mathrm{N} \mathrm{dm}^{-1}$ recomendada por Dias et al. (2012) para mudas de goiabeira cv. Paluma propagadas por estacas herbáceas, sendo esta correspondente à dose de $100 \%$ de N.

As águas salinas foram preparadas pela adição de quantidades de sais de $\mathrm{NaCl}, \mathrm{CaCl}_{2} \cdot 2 \mathrm{H}_{2} \mathrm{O}$ e $\mathrm{MgCl}_{2} \cdot 6 \mathrm{H}_{2} \mathrm{O}$, na proporção equivalente de 7:2:1, relação esta predominante nas principais fontes de água disponíveis para irrigação no Nordeste brasileiro (MEDEIROS, 1992), obedecendo-se a relação entre $\mathrm{CEa}$ e a concentração dos sais $\left(\mathrm{mmol}_{\mathrm{c}} \mathrm{L}^{-1}=\mathrm{CE}\right.$ x 10) (RHOADES et al., 1992).

Foi utilizada a cv. de goiabeira Paluma, por se tratar de um genótipo vigoroso, de fácil propagação, com tolerância a pragas e doenças, principalmente à ferrugem (Puccinia psidii Wint.), e por ser uma das mais cultivadas no Nordeste do (MENDONÇA et al., 2011).

O semeio foi realizado em 18 de março de 2014, usando-se quatro sementes por tubete, na profundidade de 1,0 $\mathrm{cm}$. Utilizou-se tubetes plásticos com dimensões de $19 \mathrm{~cm}$ de altura e $6,3 \mathrm{~cm}$ de diâmetro, capacidade $288 \mathrm{~cm}^{-3}$, e abertura na parte inferior para permitir livre drenagem. Estes recipientes foram dispostos em bandejas com capacidade para 54 tubetes, apoiadas em bancadas metálicas (cantoneiras), a uma altura de $0,8 \mathrm{~m}$ do solo.

No preenchimento dos tubetes foi utilizado substrato composto de Neossolo flúvico + areia + esterco bovino curtido na proporção de 82,15 e $3 \%$, respectivamente. As características físicas e químicas do substrato (Tabela 1) foram analisadas no Laboratório de Solos e Plantas do CCTA/UFCG, conforme metodologia de Claessen (1997).

Após as plântulas apresentarem dois pares de folhas verdadeiras totalmente expandidas, realizou-se o desbaste, deixando-se apenas uma plântula por tubete, a de melhor vigor.

A aplicação das águas salinas teve início aos 25 dias após a emergência de plântulas (DAE). As irrigações foram feitas, conforme o tratamento, com base na necessidade hídrica da planta, determinada pelo processo de lisimetria de drenagem, sendo aplicado diariamente o volume retido no tubete, determinado pela diferença entre o volume aplicado e o volume drenado da irrigação anterior. As irrigações foram feitas duas vezes ao dia, sendo no início da manhã e final da tarde. Aplicou-se a cada quinze dias, uma fração de lixiviação de $15 \%$ com base no volume aplicado neste período, de modo a reduzir a salinidade do extrato de saturação do substrato. 
Tabela 1: Características físicas e químicas do substrato utilizado no experimento.

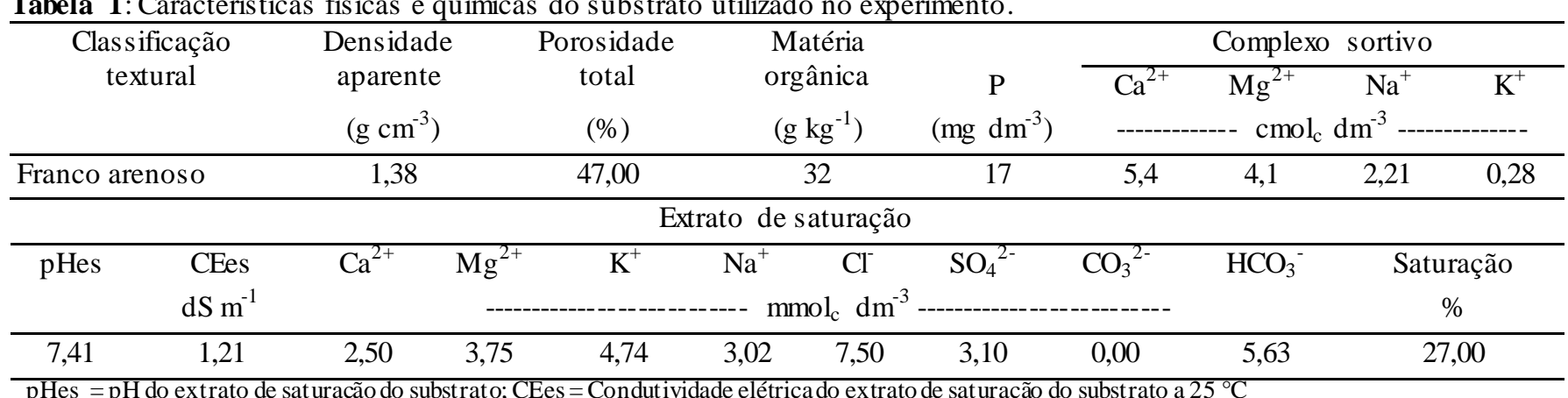

pHes $=$ pH do extrato de sat uração do substrato; $\mathrm{CEes}=$ Condutividade elétrica do ex trato de sat uração do substrato a $25^{\circ} \mathrm{C}$

A adubação nitrogenada iniciou-se aos 25 DAE, dividida em 14 aplicações em partes iguais, realizadas semanalmente, onde se utilizou como fonte de nitrogênio a ureia $(45 \%$ de $\mathrm{N})$, com aplicações realizadas via fertirrigação com água de condutividade elétrica de $0,3 \mathrm{dS} \mathrm{m}^{-1}$ para todos os tratamentos.

Aos 180 DAE avaliou-se nas mudas de goiabeira a altura de plantas (AP), diâmetro de caule (DC), número de folhas (NF), área foliar (AF), taxa de crescimento absoluto da altura de plantas (TCAap), taxa de crescimento absoluto do diâmetro do caule (TCAdc) e massa seca total de plantas (MST).

A AP foi determinada medindo-se as plantas da superfície do solo até ponto de inserção do meristema apical. Avaliou-se o DC a uma altura de $4 \mathrm{~cm}$ do colo da planta. A determinação do NF foi feita por contagem de folhas que estavam com o limbo foliar totalmente aberto. A AF foi determinada, conforme recomendação de Lima et al. (2012), considerando a eq. 1 :

$$
\mathrm{AF}=0,3205 * \mathrm{C}^{2,0412}
$$

Onde:

$\mathrm{AF}=$ área foliar $\left(\mathrm{cm}^{2}\right) ; \mathrm{C}=$ comprimento da nervura principal da folha $(\mathrm{cm})$.

A TCAap e TCAdc foram determinadas no período de 1 a 180 DAE, de acordo com metodologia descrita por Benincasa (2003), conforme as Eq. 2 e 3.

$$
\begin{aligned}
& \text { TCAap }=\frac{\left(\mathrm{AP}_{2}-\mathrm{AP}_{1}\right)}{\left(\mathrm{t}_{2}-\mathrm{t}_{1}\right)} \\
& \text { TCAdc }=\frac{\left(\mathrm{DC}_{2}-\mathrm{DC}_{1}\right)}{\left(\mathrm{t}_{2}-\mathrm{t}_{1}\right)}
\end{aligned}
$$

Em que:

TCAap $=$ taxa de crescimento absoluto da altura de planta $\left(\mathrm{cm} \mathrm{dia}^{-1}\right)$;

TCAdc $=$ taxa de crescimento absoluto do diâmetro do caule $\left(\mathrm{mm} \mathrm{dia}^{-1}\right)$;

$\mathrm{AP}_{1}=$ altura de planta $(\mathrm{cm})$ no tempo $\mathrm{t}_{1}$

$\mathrm{AP}_{2}=$ altura de planta $(\mathrm{cm})$ no tempo $\mathrm{t}_{2}$

$\mathrm{DC}_{1}=$ diâmetro do caule $(\mathrm{mm})$ no tempo $\mathrm{t}_{1}$;

$\mathrm{DC}_{2}=$ diâmetro do caule $(\mathrm{mm})$ no tempo $\mathrm{t}_{2}$.

A FST foi determinada após secagem do material em estufa de circulação forçada de ar, mantida na temperatura de $65{ }^{\circ} \mathrm{C}$ até obtenção de massa constante, que em seguida foi pesada em balança de precisão de $0,001 \mathrm{~g}$.
Os dados obtidos foram avaliados mediante análise de variância pelo teste $F$ em nível de 0,05 e 0,01 de probabilidade e nos casos de significância, realizou-se análise de regressão linear e polinomial quadrática utilizando do software estatístico SISVAR/UFLA. A escolha da regressão foi feita mediante melhor ajuste em base de coeficiente de determinação $\left(\mathrm{R}^{2}\right)$ e levando-se em consideração uma provável explicação biológica.

\section{RESULTADOS E DISCUSSÃO}

Constata-se com base no resumo da análise de variância (Tabela 2) que foi significativa $(p<0,05)$ a interação entre salinidade da água de irrigação $\mathrm{x}$ doses de nitrogênio sobre o DC e a TCAdc aos 180 DAE. Outrossim, verifica-se que houve efeito significativo $(\mathrm{p}<0,01)$ is olado do fator salinidade para NF, AF e MST, e doses de nitrogênio sobre as variáveis de AP, NF, AF, TCAap e MST.

Analisando a interação salinidade $\mathrm{x}$ doses de nitrogênio (Figuras 1A e 1B), constata-se que o uso da dose de $70 \%$ de $\mathrm{N}$ não causou diferença significativa sobre o DC e a TCAdc com o aumento da salinidade da água de irrigação, proporcionando médias de $3,41 \mathrm{~mm}$ e $0,017 \mathrm{~mm} \mathrm{dia}{ }^{-1}$, respectivamente. Verifica-se que apesar do aumento da $\mathrm{CEa}$ até o nível de $3,5 \mathrm{dS} \mathrm{m}^{-1}$, o valor destas variáveis permaneceu constante, sugerindo que esta dose possa ter amenizado o efeito da salinidade da água de irrigação.

No uso das demais doses foi observada diferença significativa. A adubação com a dose de $100 \%$ de $\mathrm{N}$ exerceu efeito quadrático sobre o DC e a TCAdc, cujos valores superiores $\left(3,38 \mathrm{~mm}\right.$ e $0,017 \mathrm{~mm} \mathrm{dia}{ }^{-1}$, respectivamente) foram obtidos no nível de $\mathrm{CEa}$ de $1,7 \mathrm{dS} \mathrm{\textrm {m } ^ { - 1 }}$, sugerindo também que esta dose possa ter amenizado o efeito do estresse salino sobre estas variáveis até este nível salino.

De acordo Blanco et al. (2008) o aumento da adubação nitrogenada em condições de salinidade, aumenta a absorção de $\mathrm{NO}_{3}$ em relação ao $\mathrm{Cl}$, reduzindo a relação $\mathrm{Cl} / \mathrm{N}$ nas folhas, o qual reestabelece o equilíbrio nutricional, sugerindo a redução do efeito do estresse salino nas plantas.

As doses de 130 e $160 \%$ de $\mathrm{N}$ afetaram negativamente o crescimento do diâmetro do caule (Figuras 1A e 1B), causando reduções lineares de 4,85 e $3,38 \%$ por aumento unitário na CEa sobre o DC, e de 5,83 e $5,45 \%$ na TCAdc. O uso destas doses de $\mathrm{N}$ pode ter contribuído como incremento do estresse salino nas plantas irrigadas com níveis crescentes de salinidade, uma vez que se utilizou a ureia como fonte de $\mathrm{N}$, a qual possui índice salino de $75 \%$ (ALCARDE et al., 2007). 
Tabela 2: Resumo da análise de variância para altura de plantas (AP), diâmetro de caule (DC), número de folhas (NF), área foliar (AF), Taxa de crescimento absoluto da altura de planta (TCAap), Taxa de crescimento absoluto do diâmetro do caule (TCAdc) e massa seca total (MST) de mudas de goiabeira cv. Paluma irrigada com águas salinizadas e sob adubação nitrogenada, aos 180 dias após a emergência - DAE.

\begin{tabular}{|c|c|c|c|c|c|c|c|}
\hline \multirow{2}{*}{ Fonte de variação } & \multicolumn{7}{|c|}{ Teste F } \\
\hline & AP & $\mathrm{DC}$ & $\mathrm{NF}^{1}$ & $\mathrm{AF}^{1}$ & TCAap & TCAdc & MST \\
\hline Salinidades (S) & $1,03^{\mathrm{ns}}$ & $6,80^{* * *}$ & $9,64^{* * *}$ & $5,29^{* * *}$ & $0,96^{\mathrm{ns}}$ & $6,92^{* * *}$ & $12,05^{* * *}$ \\
\hline Reg. linear & $2,72^{\mathrm{ns}}$ & $13,27^{* *}$ & $37,14^{* *}$ & $13,18^{* *}$ & $2,43^{\mathrm{ns}}$ & $13,72^{* *}$ & $28,89^{* *}$ \\
\hline Reg. quadrática & $1,02^{\mathrm{ns}}$ & $10,78^{* *}$ & $1,064^{\mathrm{ns}}$ & $6,42^{*}$ & $0,99^{\mathrm{ns}}$ & $10,47^{* *}$ & $18,83^{* *}$ \\
\hline Doses de N (DN) & $15,90^{* *}$ & $36,32^{* *}$ & $13,16^{* *}$ & $11,72^{* *}$ & $14,98^{* *}$ & $37,05^{* *}$ & $44,81^{* *}$ \\
\hline Reg. linear & $43,23^{* *}$ & $104,68^{* *}$ & $32,91^{* *}$ & $28,39^{* *}$ & $40,89^{* *}$ & $106,28^{\mathrm{ns}}$ & $129,62^{* *}$ \\
\hline Reg. quadrática & $4,47^{*}$ & $0,76^{\mathrm{ns}}$ & $4,23^{*}$ & $6,46^{*}$ & $4,04^{*}$ & $0,76^{* *}$ & $3,29^{\mathrm{ns}}$ \\
\hline Interação $\mathrm{S}^{*} \mathrm{DN}$ & $0,31^{\mathrm{ns}}$ & $2,07^{*}$ & $0,60^{\mathrm{ns}}$ & $0,58^{\mathrm{ns}}$ & $0,28^{\mathrm{ns}}$ & $2,32^{*}$ & $1,58^{\mathrm{ns}}$ \\
\hline Bloco & $1,15^{\mathrm{ns}}$ & $3,93^{*}$ & $5,13^{* *}$ & $2,14^{\mathrm{ns}}$ & $0,97^{\mathrm{ns}}$ & $4,48^{* *}$ & $0,55^{\mathrm{ns}}$ \\
\hline $\mathrm{CV}(\%)$ & 13,03 & 6,28 & 12,63 & 14,94 & 15,09 & 8,47 & $17,17^{\mathrm{ns}}$ \\
\hline
\end{tabular}

$\mathrm{ns}, * * *$ respectivamente não significativos, significativo a $\mathrm{p}<0,01$ e $\mathrm{p}<0,05 ;{ }^{1}$ análise est atística realizada após transformação de dados em $\sqrt{\mathrm{X}}$.

Figura 1: Diâmetro do caule - DC (A) e taxa de crescimento absoluto de diâmetro do caule - TCAdc (B) de mudas de goiabeira cv. Paluma em função da salinidade da água de irrigação - CEa, adubadas com diferentes doses de nitrogênio (N) aos 180 dias após a emergência - DAE.

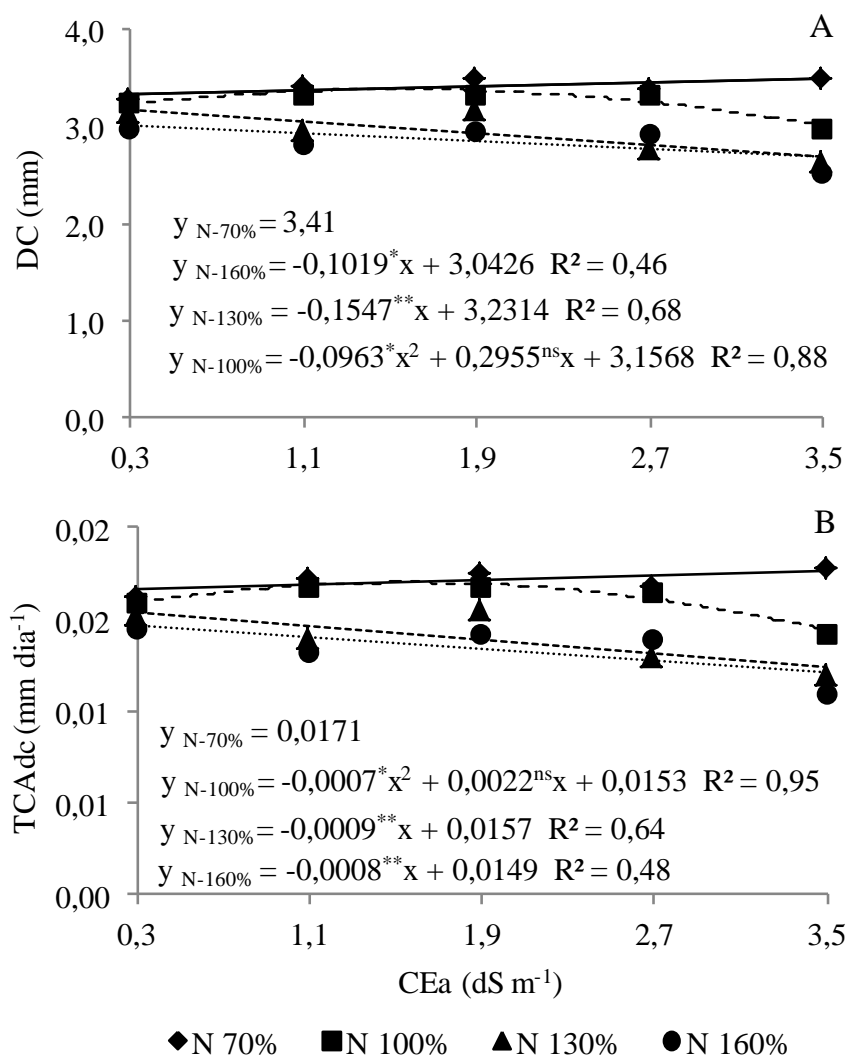

$\mathrm{O}$ aumento da salinidade na água de irrigação a partir de $0,3 \mathrm{dS} \mathrm{m}^{-1}$ reduziu de forma linear o NF por planta das mudas de goiabeira cv. Paluma (Figura 2), causando decréscimo de $56,53 \%$ (5,74 folhas) nas plantas irrigadas com maior $\mathrm{CEa}$ $\left(3,5 \mathrm{ds} \mathrm{m}^{-1}\right)$ em relação as plantas que receberam CEa de 0,3 ds $\mathrm{m}^{-1}$. Semelhantemente, Gurgel et al. (2007) verificaram reduções de 51,06 e $54,18 \%$ sobre o NF de porta-enxerto de goiabeira nas cv. Rica e Ogawa irrigadas com CEa de 3,5 ds $\mathrm{m}^{-1}$ em relação às plantas que receberam com $\mathrm{CEa}$ de $0,5 \mathrm{ds}$ $\mathrm{m}^{-1}$, aos 80 DAE.

A redução do número de folhas em condições de estresse salino constitui um mecanismo de alteração morfológica e anatômica nas plantas, que refletem na redução da transpiração como alternativa para manter a baixa absorção de água salina (OLIVEIRA et al., 2010).

Figura 2: Número de folhas - NF de mudas de goiabeira cv. Paluma em função da salinidade da água de irrigação - CEa aos 180 dias após a emergência - DAE.

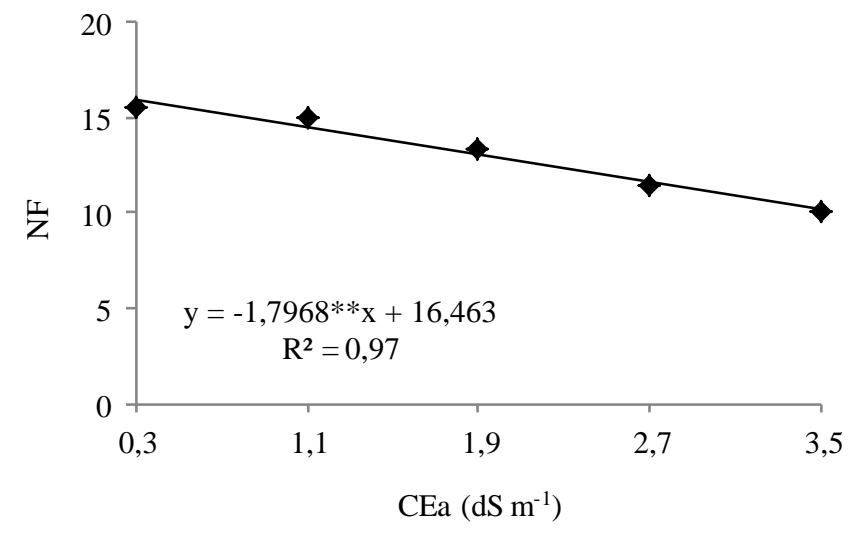

A AF e a MST sofreram efeito quadrático pelo o incremento na salinidade da água de irrigação (Figuras $3 \mathrm{~A}$ e 3B), que conforme equações de regressão, atingiram valores crescentes até o nível de CEa de $1,3 \mathrm{dS} \mathrm{m}^{-3}$, a partir de onde ocorreram decréscimos, sobretudo, ainda mantendo valores superiores em relação às plantas irrigadas com menor $\mathrm{CEa}$ $\left(0,3 \mathrm{dS} \mathrm{m}^{-1}\right)$ até o nível de salinidade da água de $2,2 \mathrm{ds} \mathrm{m}^{-1}$ (Figuras 3A e 3B). Isto caracteriza a tolerância destas variáveis ao estresse salino no período de 180 DAE.

$\mathrm{O}$ limite de tolerância das plantas à salinidade pode estar relacionado a vários fatores, dentre eles ao ajustamento osmótico, que é resultante do acúmulo de solutos orgânicos compatíveis no citoplasma que contribui com a absorção de água e a manutenção dos processos fisiológicos (HOPKINS, 1999), ou mesmo, a seletividade na absorção de íons, a 
compartimentalização e a exclusão de sais para o espaço apoplástico (WILLADINO; CAMARA, 2010).

Figura 3: Área foliar - AF (A) e massa seca total de plantas MST (B) de mudas de goiabeira cv. Paluma em função da salinidade da água de irrigação aos 180 dias após a emergência - DAE.
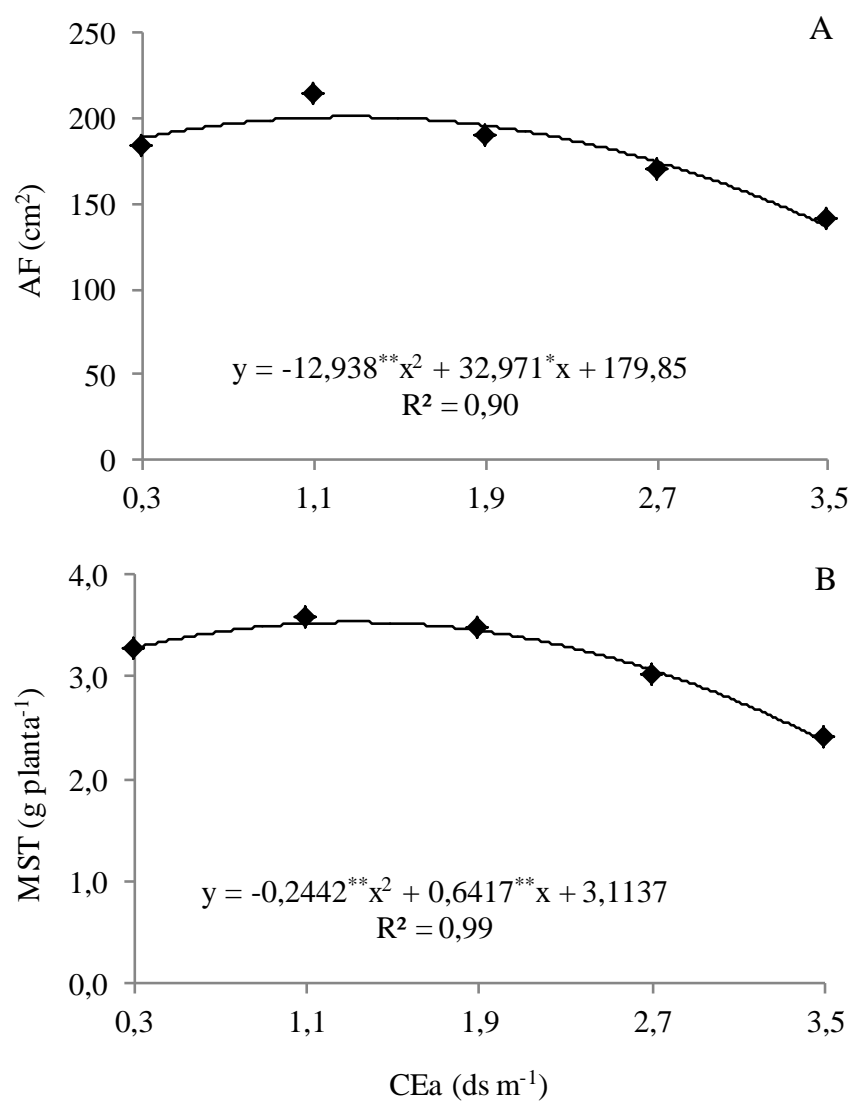

Constata-se (Figuras 4A e 4B) que o aumento na dose de $\mathrm{N}$ promoveu melhor ajuste dos dados de altura das plantas em equações quadráticas, onde os maiores valores de $\operatorname{AP}(36,03$ $\mathrm{cm})$ e a TCAap $\left(0,211 \mathrm{~cm} \mathrm{~cm}^{-1}\right)$ foram obtidos entre as doses de $73-76 \%$ e $70-80 \%$ de $\mathrm{N}$, respectivamente. O ganho de AP foi de $0,05 \%(0,02 \mathrm{~cm})$, ocorrendo apenas entre as doses de $70-73 \%$ de $\mathrm{N}$, enquanto que de 73 a $76 \%$ de $\mathrm{N}$, o valor manteve-se constante. A TCAap não obteve ganhos com o aumento da dose de $\mathrm{N}$, a qual manteve-se constante quando as plantas foram adubadas com as doses de 70 a $80 \%$ de $\mathrm{N}$. Desse modo, sugere-se que a adubação nitrogenada entre as doses de $70\left(541 \mathrm{mg}\right.$ de $\left.\mathrm{N} \mathrm{dm}^{-3}\right)$ e $80 \%$ de $\mathrm{N}(618,4 \mathrm{mg}$ de $\mathrm{N}$ $\mathrm{dm}^{-3}$ ) são propícias para o maior crescimento das plantas em altura.

Diferentemente, Dias et al. (2012) verificaram maior exigência de $\mathrm{N}$ (762 $\mathrm{mg}$ de $\mathrm{N} \mathrm{dm}^{-3}$ ) por mudas de goiabeira cv. Paluma para que fosse obtida maior AP. Esta discrepância pode estar relacionada à forma de aplicação do fertilizante, sendo que Dias et al. (2012) fez a adubação com N utilizando ureia em cobertura, podendo ter causado maiores perdas por volatização, sendo necessário uma maior dose para suprir as plantas, enquanto que as doses aplicadas no experimento (Figuras 4A e 4B) foram aplicadas via fertiirrigação, propiciando maior eficiência de aplicação do fertilizante utilizado (CARRIJO et al., 2004), sendo desta maneira, as doses de 70 (541 mg de $\mathrm{N} \mathrm{dm}^{-3}$ ) a $80 \%$ de $\mathrm{N}(618,4 \mathrm{mg}$ de $\mathrm{N}$ $\mathrm{dm}^{-3}$ ) suficiente para promover maior crescimento das plantas em altura.

Figura 4: Altura de planta - AP (A) e taxa de crescimento absoluto de altura de planta - TCAap (B) de mudas de goiabeira cv. Paluma em função de doses de nitrogênio aos 180 dias após a emergência - DAE
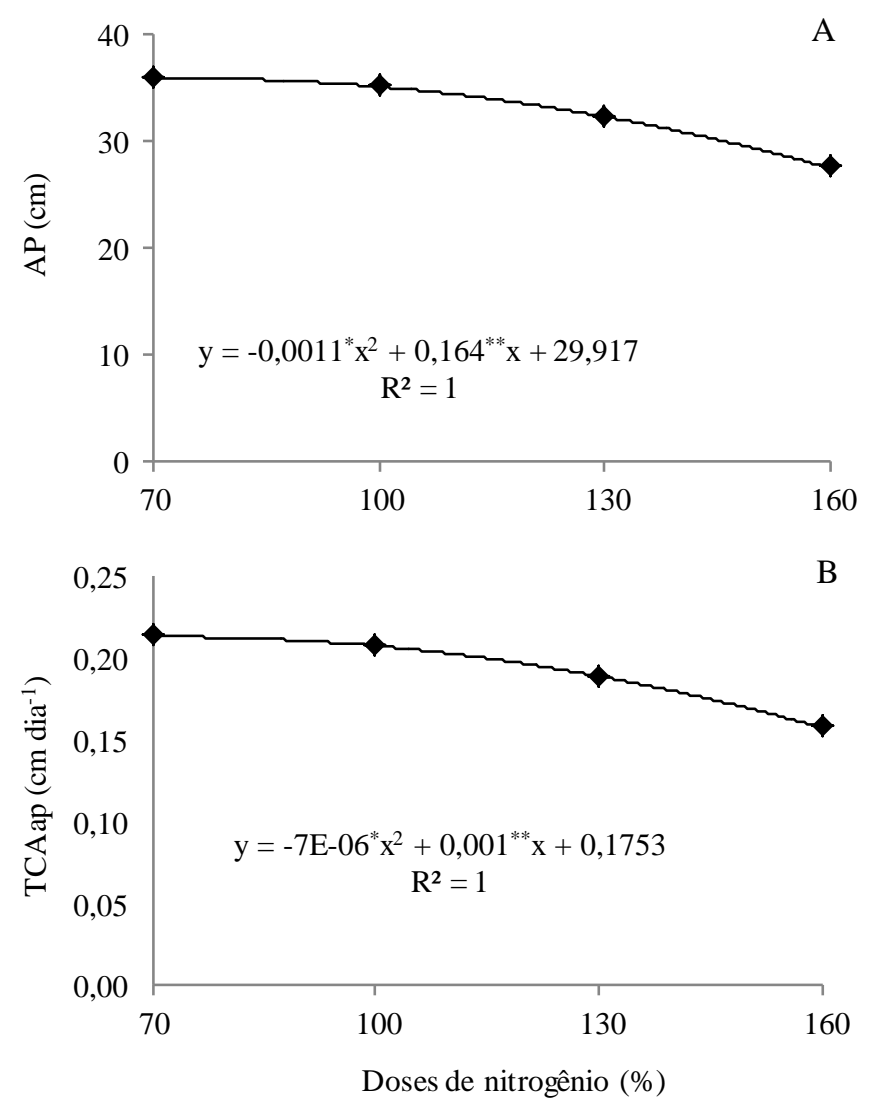

$\mathrm{O}$ aumento na adubação nitrogenada contribuiu com a elevação do NF e da AF (Figuras 5A e 5B), onde o melhor ajuste dos dados ocorreu em equações quadráticas, verificando-se que o maior NF (14,88 folhas por planta) foi obtido entre as doses $77-81 \%$ de N, enquanto a AF $(208,43$ $\mathrm{cm}^{2}$ ) atingiu maior valor na dose de $90 \%$ de N. A área foliar foi a que mais respondeu a aumento da adubação nitrogenada, obtendo ganho de $3,20 \%$, enquanto que o NF teve aumento apenas de $0,4 \%$ em relação às plantas que receberam a dose de $70 \%$ de N.

De acordo com Silva et al. (2014) o nitrogênio é considerado um dos principais agentes de crescimento das plantas e de desenvolvimento foliar. A explicação pode está relacionada às funções deste elemento nas plantas, uma vez que, desempenha função estrutural e funcional, fazendo parte de diversos compostos orgânicos vitais para o vegetal, como hormônios de crescimento, aminoácidos, proteínas, clorofila, ácidos nucleicos, entre outros (TAIZ; ZAIGER, 2013).

Percebe-se (Figura 5A e 5B) que o incremento da adubação nitrogenada a partir das doses de 81 e $90 \%$ de $\mathrm{N}$ causou decréscimos sobre o NF e a AF, respectivamente. Outrossim verifica-se que a AP e a TCAap apresentaram efeito semelhante quando utilizou-se doses acima de 76 e $80 \%$, respectivamente. Isto pode estar associado a algum desequilíbrio nutricional causado pelo excesso do $\mathrm{N}$ quando se utilizou doses acima do exigido pelas plantas, ou mesmo, à 
desordens fisiológicas induzidas pelo excesso de sais presentes no substrato em decorrência de aplicações de doses crescentes de ureia (LOPES et al., 1999).

Figura 5: Número de folhas - NF (A) e área foliar - AF (B) de mudas de goiabeira cv. Paluma em função de doses de nitrogênio aos 180 dias após a emergência - DAE.
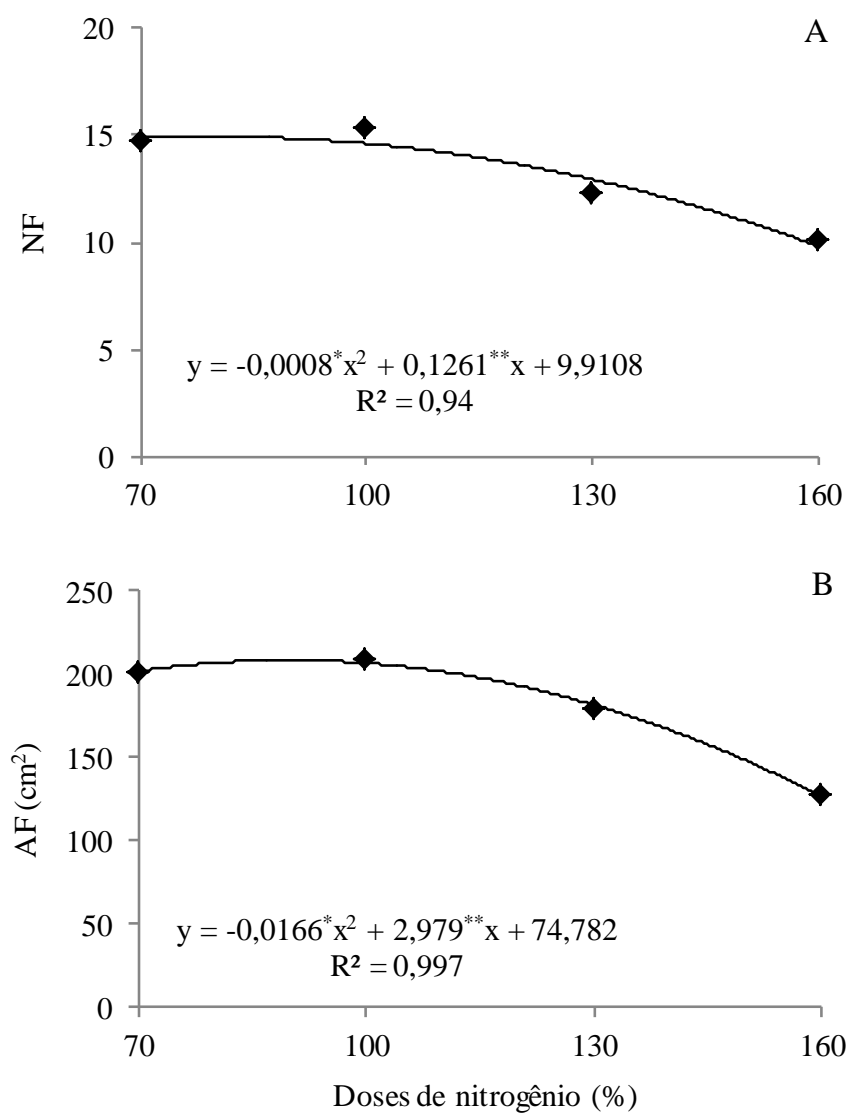

Observa-se (Figura 6) que o aumento da adubação

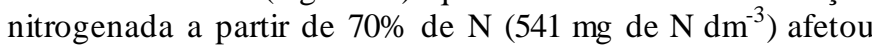
negativamente o acúmulo de MST das mudas de goiabeira, causando decréscimo linear de 15,27\% (0,62 g) para cada aumento de $30 \%$ na dose de $\mathrm{N}$.

Uma possível explicação para este efeito pode ser a acidificação do meio, haja vista que o adubo utilizado foi a uréia, cujo desdobramento pela uréase libera $\mathrm{H}^{+}$ (MALAVOLTA, 2006), ou mesmo, pelo incremento do estresse salino nas plantas em função da aplicação da ureia combinada com a salinidade da água de irrigação.

Além disso, como a uréia no solo transforma-se rapidamente em amônio, acredita-se que possivelmente em concentrações crescentes as mudas possam ter absorvido maior quantidade de $\mathrm{N}$ na forma amoniacal, propiciando um efeito tóxico do amônio à planta conforme relatado por Silva et al. (2014), quando avaliaram efeito de doses crescentes de $\mathrm{N}$ sobre a matéria seca de mudas de jaqueira.
Figura 6: Massa seca total de plantas (MST) de mudas de goiabeira cv. Paluma em função de doses de nitrogênio aos 180 dias após a emergência - DAE.

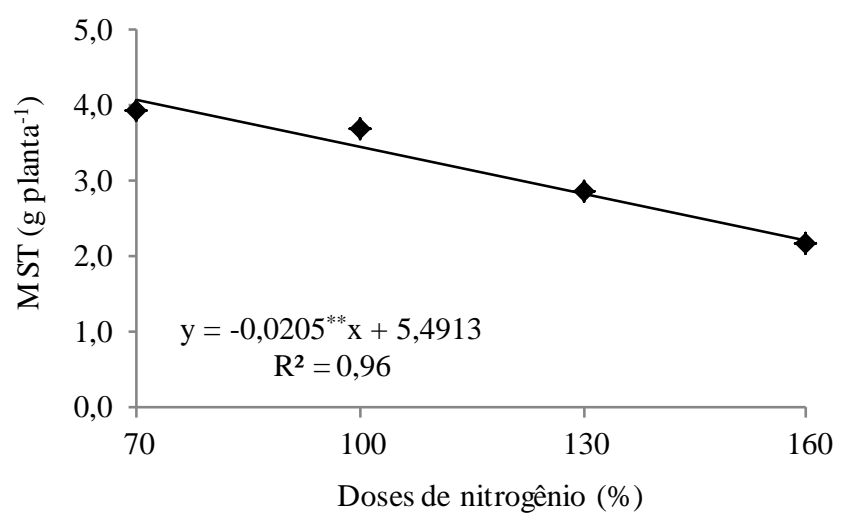

\section{CONCLUSÕES}

A adubação nitrogenada nas doses de 70 (541 mg de N $\left.\mathrm{dm}^{-3}\right)$ e $100 \%$ de $\mathrm{N}\left(773 \mathrm{mg}\right.$ de $\left.\mathrm{N} \mathrm{dm}^{-3}\right)$ reduz o efeito da salinidade da água de irrigação sobre o diâmetro do caule de mudas de goiabeira cv. Paluma.

As mudas adubadas com as doses variando de 70 (541

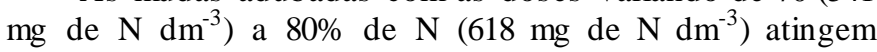
maior crescimento em altura de planta, número de folhas e área foliar.

A área foliar e a massa seca total de mudas de goiabeira atingem maiores valores no nível de CEa de $1,3 \mathrm{dS} \mathrm{m}^{-1}$.

\section{REFERÊNCIAS}

ALCARDE, C. A. Fertilizantes. In: NOVAES, R. F.; ALVAREZ V, V. H.; BARROS, N. F.; FONTES, R. L. F.; CANTARUTTI, R. B.; NEVES, J. C. L. Fertilidade do solo. 1 ed., Viçosa: SBCS, 2007. p. 737-768.

APSE, M.P.; BLUMWALD, E. $\mathrm{Na}^{+}$transport in plants. FEBS Letters, v.581, n.12, p.2247-2254, 2007.

BENINCASA, M. M. P. Análise de crescimento de plantas: noções básicas. 2 ed. Jaboticabal: FUNEP, 2003. 41 p.

BLANCO, F. F.; FOLEGATTI, M. V.; HENRIQUES NETO, D. Doses de N e K no tomateiro sob estresse salino: I. Concentração de nutrientes no solo e na planta. Revista Brasileira de Engenharia Agrícola e Ambiental, v.12, n.1, p.26-33, 2008.

CARRIJO, O. A.; SOUZA, R. B.; MAROUELLI, W. A.; ANDRADE, R. J. Fertirrigação de hortaliças. Brasília: EMBRAPA, 2004. 13 p. (Circular técnica, n. 32).

CAVALCANTE, L. F. CAVALCANTE, Í. H. L.; PEREIRA, K. S. N.; OLIVEIRA, F. A.; GONDIM, S. C.; ARAÚJO, F. A. R. Germination and initial growth of guava plants irrigated with saline water. Revista Brasileira de Engenharia Agrícola e Ambiental, v.9, n.4, p.515-519, 2005. 
CAVALCANTE, L. F; VIEIRA, M. S.; SANTOS, A. F.; OLIVEIRA, W. M.; NASCIMENTO, J. A. M. Água salina e esterco bovino líquido na formação de mudas de goiabeira cultivar Paluma. Revista Brasileira de Fruticultura, v.32, n.1, p. 251-261, 2010.

ClAESSEN, M. E. C. (Org.). Manual de métodos de análise de solo. 2.ed. rev. atual. Rio de Janeiro: Embrapa-CNPS, 1997. 212p.

DIAS, M. J. T.; SOUZA, H. A.; NATALE, W.; MODESTO, V. C.; ROZANE, D. E. Adubação com nitrogênio e potássio em mudas de goiabeira em viveiro comercial. Ciências Agrárias, v. 33, suplemento 1, p. 2837-2848, 2012.

FRANCO, F. C.; PRADO, R. M.; BRACHIROLLI, L. F.; ROZANE, D. E. Curva de crescimento e marcha de absorção de macronutrientes em mudas de goiabeira. Revista Brasileira de Ciência do Solo, v. 31, n. 6, p. 1429-1437, 2007.

GONZAGA NETO, L. Produção de goiaba. Fortaleza: Instituto Frutal, 2007. 64 p.

GURGEL, M. T.; GHEYI, H. R.; FERNANDES, P. D.; SANTOS, F. J. S.; NOBRE, R. G. Crescimento inicial de porta-enxertos de goiabeira irrigados com águas salinas. Revista Caatinga, v.20, n.2, p.24-31, 2007.

HOPKINS, G.W. Introduction to plant physiology, New York: John Wiley \& Sons, 1999. 512 p.

INSTITUTO BRASILEIRO DE GEOGRAFIA E ESTATÍSTICA-IBGE. Produção agrícola municipal, Rio de Janeiro, v. 39, p.1-101, 2012.

LIMA, L. G. S.; ANDRADE, A. C.; SILVA, R. T. L.; FRONZA, D.; NISHIJIMA, T. Modelos matemáticos para estimativa de área foliar de goiabeira (Psidium guajava L.). In: 64 ${ }^{\text {a }}$ REUNIÃO ANUAL DA SBPC. São Luiz: UFMA, 2012.

LOPES, P. S. N.; MELO, B.; CUNHA NETO, F. R.; RAMOS, J. D.; CARVALHO, J. G. Adubação nitrogenada e substratos no crescimento de mudas de maracujazeiro amarelo em tubetes. Revista da Universidade de Alfenas, v.5, p.3-8, 1999.

MALAVOLTA, E. Manual de nutrição mineral de plantas. São Paulo: Agronômica Ceres, 2006. 638 p.

MEDEIROS, J. F. Qualidade da água de irrigação e evolução da salinidade nas propriedades assistidas pelo "GAT" nos Estado do RN, PB e CE. 1992. $173 \mathrm{f}$. Dissertação (Mestrado em Engenharia Agrícola) niversidade Federal da Paraíba, Campina Grande, 1992.

MENDONÇA, V. Cultura da goiaba. Mossoró: UFERSA, 2011. $40 \mathrm{p}$.
MUNNS, R. Genes and salt tolerance: bringing them together. New Phytologist, v.167, p. 645-663, 2005.

NEVES, A. L. R.; LACERDA, C. F.; GUIMARÃES, F. V. A.; HERNANDEZ, F. F. F.; SILVA, F. B.; PRISCO, J. T.; GHEYI, H. R. Acumulação de biomassa e extração de nutrientes por plantas de feijão-de-corda irrigadas comágua salina emdiferentes estádios de desenvolvimento. Ciência Rural, v.39, n.3, p. 758-765, 2009.

OLIVEIRA, F. A. de; OLIVEIRA, F. R. A; CAMPOS, M. S.; OLIVEIRA, M. K. T; MEDEIROS, J. F.; SILVA, O. M. P. Interação entre salinidade e fontes de nitrogênio no desenvolvimento inicial da cultura do girassol. Revista Brasileira de Ciências Agrárias, Recife, v. 5, n. 4, p. 479-484, 2010.

RHOADES, J. S.; KANDIAH, A.; MASHALI, A. M. Uso de águas salinas para produção agrícola. Tradução de GHEYI, H. R.; SOUZA, J.; QUEIROZ, J. E. Capina Grande: UFPB, 2000, 117p. (Estudos da FAO, Irrigação e Drenagem, 48 revisado).

SILVA JUNIOR, L. G. A. GHEYI, H. R.; MEDEIROS, J. F. Composição química de águas do cristalino do Nordeste Brasileiro. Revista Brasileira de Engenharia Agrícola e Ambiental, v.3, n.1, p.11-17, 1999.

SILVA, C. P.; GARCIA, K. G. V.; TOSTA, M. S.; CUNHA, C. S. M.; NASCIMENTO, C. D. V. Adubação nitrogenada no crescimento inicial de mudas de jaqueira. Enciclopédia Biosfera, v.10, n.18; p. 174-180, 2014.

SOARES, L. A. A.; NOBRE, R. G.; GHEYI, H. R.; LIMA, G. S.; SILVA, A. O.; SOARES, S. S. Componentes de crescimento da mamoneira cultivada com águas salinas e doses de nitrogênio. Irriga, Edicão Especial, p. 40 - 54, 2012.

TAIZ, L.; ZEIGER, E. Fisiologia vegetal. 5. ed. Porto Alegre: Artmed, 2013. 954p.

TÁVORA, F. J. A. F.; FERREIRA, R. G.; HERNANDEZ, F. F. F. Crescimento e relações hídricas em plantas de goiabeira submetidas a estresse salino com Nacl. Revista Brasileira de Fruticultura, v. 23, n. 2, p. 441446, 2001.

WILLADINO, L.; CAMARA, T. R. Tolerância das plantas à salinidade: Aspectos fisiológicos e bioquímicos. Enciclopédia Biosfera, v.6, n.11; p. 1-23, 